\title{
O design de moda e a celebridade endossadora
}

\section{Fashion design and the endorser celebrity}

SOUZA, Teresa Campos Viana; doutoranda; Universidade do Estado de Minas Gerais tecacviana@gmail.com

SILVA, Sérgio Antônio; Doutor; Universidade do Estado de Minas Gerais

sergio.antonio74@hotmail.com

ADVERSE, Angélica; Doutora; Universidade do Estado de Minas Gerais

adverseangelica@gmail.com

HORTA, Anderson; Doutor; Centro Universitário de Belo Horizonte (Uni-BH)

andersonhorta@gmail.com

RIBEIRO, Rita; Doutora; Universidade do Estado de Minas Gerais

rribeiroed@gmail.com

\section{Resumo}

O presente artigo pretende discutir como a sociedade de consumo se formou, as mudanças que as novas gerações estão trazendo e também expor as mudanças nessa sociedade, como os consumidores estão preocupados com a procedência dos produtos e como a cultura de massa influencia no poder da compra. A celebridade endossadora se torna peça importante na apresentação, na venda de produtos e na influência sobre os potenciais consumidores seja de produtos, ideias ou serviços. As marcas compreendem essa influencia e a utilizam para gerar desejo nos consumidores. Pretende também discutir como percebemos a participação dos consumidores com as transformações dos seus hábitos, novas exigências e as repercussões no próprio consumo.

Palavras Chave: design de moda, celebridade e hábitos de consumo.

\section{Abstract}

This article aims to discuss how the consumer society has formed, the changes that the new generations are bringing and also expose the changes in that society, how consumers are concerned with the origin of the products and how the mass culture influences the purchasing power. The endorser celebrity becomes an important part of the presentation, the sale of products and the influence on potential consumers of products, ideas or services. Some brands understands this influence and use it to generate desire in consumers. It also intends to discuss how we perceive the participation of the consumers with the changes of their habits, new demands and the repercussions in the own consumption.

Keywords: fashion design, celebrity, consumer habits. 


\section{Introdução}

As mudanças que ocorreram em todos os âmbitos da sociedade no final do século XIX e início do século XX trouxeram transformações na forma como se consumia. As revoluções industriais foram importantes para a mudança de pensamento do homem da época. Esses homens buscavam, através dessas revoluções, modificar o que não estava agradando. Cada país se desenvolveu de forma diferente, baseado em suas condições sociais, econômicas e culturais. Com isso, houve uma grande migração da população do campo para a cidade e uma mudança significativa nas necessidades de consumo da população da época. A chegada de produtos novos despertava na população uma suposta necessidade de compra. (Colombo et al., 2008).

A sociedade utiliza os bens de consumo a partir do nascimento do capitalismo e apropriase deles e os transforma em produtos de desejo e os consome com regularidade. Segundo Bauman (2008, p.37) o "consumo é algo banal [...]. Uma atividade que fazemos todos os dias. Muitas vezes sem planejamento antecipado. O fenômeno do consumo tem raízes tão antigas quanto os seres vivos". Para o autor, estamos tão acostumados com o ato de consumir que, muitas vezes, não nos preocupamos com ele, o que o torna um fenômeno sem planejamento. 0 homem consome todo tipo de produto, muitas vezes, sem se preocupar com a procedência dessa mercadoria.

Na Antiguidade, a forma de consumo era praticada em sistema de troca, de escambo. Segundo Madureira (2014, p.9): "O escambo pode ser definido como uma forma de comércio em que a troca de mercadorias se faz sem a utilização de dinheiro." Com a modernidade, mais especificamente na Idade Média, com o surgimento dos primeiros sistemas bancários na França e na Inglaterra, que a forma de consumo foi se alterando. O homem passa, então, a comprar produtos em mercados e lojas com a moeda local. Essa lógica de consumo perdurou e ainda perdura. Hoje, já podemos afirmar que existem outras formas de consumo, além da forma moderna de se pagar por um serviço ou produto com dinheiro. A loja de roupas de criança Arena Baby, por exemplo, permite que o cliente use a troca de produtos como forma de pagamento. 0 cliente leva roupas de criança usadas e que estão em bom estado de conservação, essas peças são avaliadas e servem como moeda de troca para a compra de produtos na loja. ${ }^{1}$ Podemos dizer que o método de escambo dos tempos antigos está voltando. Já existem empresas que optam por esse tipo de pagamento. Bauman (2008) ainda afirma que "o tipo de consumo muda com o tempo, com uma época. Mas geralmente, é uma versão modificada de alguma modalidade anterior."

Pode-se afirmar que essa mudança de pensamento tem se perpetuado com a geração que chamamos de millenialls. Segundo Carvalhal (2006), os valores da sociedade estão mudando com a chegada dessa nova geração. Valores como cuidado, compaixão, resiliência, aspiração por significado, preocupação com a comunidade e legado estão se tornando mais importantes para esses novos consumidores do que apenas possuir. Ainda que com um olhar otimista, senão romântico, sobre as mudanças percebidas por ele entre as novas gerações, o mundo capitalista tem mostrado uma avidez cada vez maior sobre o consumo. Isso é percebido pela degradação ambiental e escassez de produtos naturais.

O autor insiste que "as organizações precisam absorver esses valores para continuar existindo e o propósito vem transformando a vida de muitas organizações, que estão indo além do

\footnotetext{
${ }^{1}$ http://www.arenababy.com.br/
} 
lucro para potencializar seu impacto na sociedade" Carvalhal (2006).

Ainda assim, percebe-se que frequentemente a sociedade utiliza de algum tipo de endosso para comprar determinado produto ou para mudar sua forma de consumir. Lipovetsky (2009) nos mostra que a cultura de massa está inserida na moda desde os tempos do cinema e que as estrelas e ídolos contribuíram para a recuperação da indústria nos 1950.

\begin{abstract}
Se a cultura de massa está imersa na moda é também porque gravita em torno de figuras de charme com sucesso prodigioso, que impulsionam adorações e paixonites extremas: estrelas e ídolos. Desde os 1910-20, o cinema jamais deixou de fabricar estrelas, são elas que os cartazes publicitários exibem, são elas que atraem o público para as salas escuras, foram elas que permitiram recuperar a enfraquecida indústria do cinema nos anos 1950. Com as estrelas, a forma moda brilha com todo o seu esplendor, a sedução está no ápice de sua magia. (LIPOVETSKY, 2009, p.248)
\end{abstract}

Nesse contexto, as celebridades se tornam importantes atores nesse processo de endosso. Se um ator ou atriz de renome passa a divulgar determinado produto, a chance de esse produto ter sucesso nas vendas é muito maior do que sem endosso algum, conforme cita MCCRAKEN (2012):

O processo de endosso depende das propriedades simbólicas da celebridade endossadora. [...] A celebridade endossadora é definida como qualquer indivíduo que aproveita o reconhecimento público e que usa esse reconhecimento em nome de um bem de consumo ao aparecer com ele num anúncio. (MCCRAKEN, 2012 p.109)

Neste artigo pretendemos debater, portanto, as mudanças percebidas na sociedade de consumo, a relevância da celebridade endossadora na apresentação e na venda de produtos e como percebemos a participação dos consumidores com as transformações dos seus hábitos, novas exigências e as repercussões no próprio consumo.

\title{
2 A sociedade de consumo
}

Segundo Bauman (2008), a sociedade de consumo promete felicidade instantânea e perpétua para aqueles que consomem produtos e serviços. Ou seja, o homem só se sente feliz se compra algum produto aqui e agora, se fazia algum tipo de viagem ou se pudesse conhecer algum lugar inédito e esse agora se torna sucessivo sempre que o consumo de algum produto se perpetuava. Formava-se, assim, um ciclo vicioso, conforme a citação abaixo nos elucida:

A sociedade de consumo tem como base de suas alegações a promessa de satisfazer os desejos humanos em um grau de nenhuma sociedade do passado pôde alcançar, ou mesmo sonhar, mas a promessa de satisfação só permanece sedutora enquanto o desejo continua insatisfeito; mais importante ainda, quando o cliente não está plenamente satisfeito - ou seja, enquanto não se acredita que os desejos que motivaram e colocaram em movimento a busca da satisfação e estimularam experimentos consumistas tenham sido verdadeira e totalmente realizados. (BAUMAN, 2008, p.63)

O homem acredita satisfazer o seu desejo e continua feliz se está consumindo, pois, a promessa de satisfação não termina, o desejo continua insatisfeito, sempre tem mais alguma coisa para ser consumida. É importante lembrar, ainda, que existe uma parcela da população, tanto no Brasil quanto no mundo, que ainda não teve acesso aos bens de consumo produzidos pela sociedade. Essa população, no momento que as condições socioeconômicas permitirem, serão chamadas ao consumo e não há como coibir esse interesse pelas televisões, pela linha branca, 
pelos automóveis e pelo vestuário, quando esse acesso estiver disponível. Bauman (2008, p.64) ainda completa: "a sociedade de consumo prospera enquanto consegue tornar perpétua a não satisfação de seus membros (e assim, em seus próprios termos, a infelicidade deles)". Colombo et al. (2008) completa, informando-nos que, com o maior acesso às informações, a necessidade de consumir aumenta pois o desejo pelo novo também aumenta.

\begin{abstract}
Ou seja, o ser humano, ao ter mais acesso às informações, consequentemente terá mais acesso ao novo, à novidade. Logo, cria-se a necessidade de obtê-la para poder se enquadrar ao novo estilo de vida, ou para ser aceito no grupo, ou então, para não ficar "atrasado". Assim, a terceira fase da evolução da sociedade de consumo é marcada pela consolidação da lógica do efêmero, em que a busca pelo novo acelera-se, proporcionalmente à velocidade da informação. (COLOMBO et al., 2008, p. 147)
\end{abstract}

Porém, é perigoso dizer que todo tipo de consumo e todos os bens de consumo são ruins e são perigosos para a sociedade contemporânea. McCraken (2012 p.13) afirma que os bens de consumo podem ser um dos mais importantes moldes para a personalidade humana: "os bens de consumo são um importante meio de nossa sociedade. Neles depositamos nossos significados públicos e privados. Carros e roupas, por exemplo, são carregados de significados, que usamos para definir a nós mesmos". O autor ainda afirma que é perigoso dizer que o materialismo é o mal do século.

Diz que esses bens nos privaram da alta cultura, da verdadeira espiritualidade, dos ideais comunitários, do auto sacrifício e do bem comum. Bens são prisões para a personalidade. [...] Esse argumento é uma perigosa má interpretação dos fatos. [...] Cria alienação onde não é necessária, autocrítica onde não é válida e orienta nossos temores coletivos na direção errada. (MCCRAKEN, 2012 p.13)

Segundo o autor, não podemos generalizar que todo tipo de consumo é ruim e pode arruinar o mundo. Os bens de consumo podem também ser meios de entender quem somos e o que queremos levar para e da sociedade. Vivemos, hoje, em uma sociedade na qual os indivíduos têm mais acessos à informação para construir sua personalidade. Cada dia mais podemos escolher quem queremos ser e como queremos que o mundo nos veja e os bens de consumo podem nos ajudar a fazer essas escolhas. Segundo o autor, os bens de consumo:

Bens nos ajudam a fazer escolhas. Nos ajudam a tornar nossa cultura concreta e pública (por meio do MKT e do varejo). Nos ajudam a selecionar e assumir novos significados (por meio das compras). Nos ajudam a expor novos significados (por meio do uso). E nos ajudam a mudar significados (por meio da inovação). Bens nos ajudam a aprender, fazer, expor e mudar as escolhas demandadas por nossa sociedade individualista. Não são prisões, mas instrumentos para a personalidade. (MCCRAKEN, 2012 p.14)

Pensar que a sociedade de consumo é algo catastrófico e artificial é pobre e sem argumentos. Precisamos pensar "que os bens de consumo nos conquistam porque eles capturam os significados com os quais construímos nossas vidas". (McCraken, 2012) São esses significados que farão com que a sociedade se transforme.

Entretanto, há que se considerar a necessidade que a sociedade contemporânea tem de buscar um modo de vida em que o consumo, apesar de continuar existindo, seja realizado de forma a agredir menos o meio ambiente, por meio de produtos mais duráveis, com menos embalagens, com matérias-primas que agridam menos o meio ambiente, com baixo uso de energia, por exemplo. Esses são os objetivos do milênio, a moda como consumo consciente vem 
se tornando um novo mercado nos dias atuais. Schulte e Lopes (2008) confirmam que esses novos conceitos estão começando a ficar presentes nas preocupações das empresas de moda.

\begin{abstract}
Gradativamente, a preocupação com a preservação do meio ambiente, no processo de desenvolvimento de produtos, passa a fazer parte do sistema da moda. Já é possível encontrar no mercado brasileiro algumas marcas que trabalham com este valor agregado a seus produtos e este número está crescendo. (SCHULTE E LOPES, 2008, p.34)
\end{abstract}

Segundo Schulte e Lopes (2008, p.35): “O respeito pelo meio ambiente, a utilização de fibras e tintas naturais e a reciclagem de roupas e objetos usados, são a base da moda ecológica, que pouco a pouco tem conquistado os consumidores e estilistas na Itália e em outros países." Percebe-se que uma parcela considerável da sociedade está preocupada com o meio ambiente quando passa a procurar por produtos que são menos degradantes ou totalmente amigos da natureza. Para responder a essa demanda é necessário que as indústrias desenvolvam tecnologias para a produção e uso de produtos sustentáveis. Associado a isso, os bens de consumo conseguem divulgar a ideia da sustentabilidade ambiental de uma forma rápida e abrangente.

Ainda segundo as autoras:

Em alguns países já existe uma legislação rígida obrigando as indústrias a se adequarem para diminuir os danos ao meio ambiente, também há consumidores conscientes que procuram por produtos ecologicamente concebidos, que se preocupam com a natureza e com as gerações futuras. Na França, já representam $15 \%$ da população e vêm crescendo acentuadamente. Diante deste contexto, as empresas não podem mais ignorar este fenômeno, bem como não devem esquecer de divulgar sua preocupação com o meio ambiente ao desenvolverem seus produtos. (SCHULTE e LOPES, 2008 p.36)

Precisamos pensar também que os bens de consumo ajudam a destruir estereótipos e construir uma autoestima maior nas pessoas. Colombo et al. (2008, p. 147) nos apontam que: "As pessoas utilizam a moda para mostrarem como elas são ou como gostariam de ser, e a satisfação é gerada pelo reconhecimento do outro ou pela aceitação em determinado grupo." McCraken (2012), confirma esse ponto de vista:

E deixe-nos lembrar que os bens de consumo ajudam a destruir estereótipos. Na nossa sociedade, todo grupo revolucionário cria uma combinação de roupas para repudiar antigos significados e estabelecer novos. A história do feminismo na América do Norte representa, entre outras coisas, um contínuo repúdio e reinvenção da cultura material á medida que a mulher recusa roupas sexistas e cria outras que dão voz a uma nova visão de gênero. (MCCRAKEN, 2012, p.14)

É necessário marcar que temos na sociedade uma parcela da população que não consome por questões econômicas e outras alheias a ao consumo por questões culturais.

\title{
2.1 A celebridade endossadora
}

As celebridades, por terem acesso a milhões de pessoas, dada amplitude de acesso promovida pela internet e pela televisão, conseguem se tornar agentes endossadores de produtos e ideias. A forma como é endossado um produto costuma ser a garantia de sucesso de venda. Não basta somente a celebridade aparecer usando ou divulgando um produto, os consumidores, hoje, sabem se aquele endosso é verdadeiro ou algo que foi construído apenas para fazer com que eles consumam o produto, conforme cita MCCRAKEN (2012): 
A eficiência do endossador depende, em parte, dos significados que ele ou ela trazem para o processo de endosso. O número e variedade de significados contidos nas celebridades é muito grande. Distinções de tipo de status, classe, gênero, idade, personalidade e estilo de vida são representados no conjunto de celebridades disponíveis, colocando uma paleta de significados extraordinariamente variada e sutil a disposição do sistema de MKT. (MCCRAKEN, 2012 p.114)

A escolha da celebridade irá determinar o sucesso de vendas de um produto ou de uma ideia. Por exemplo, quando a empresa de cerveja Devassa escolhe a cantora Sandy para endossar seu produto. $O$ endosso dessa celebridade não foi válido, a empresa não conseguiu atingir o consumidor através dessa campanha porque a celebridade em questão já tinha anunciado diversas vezes que não gosta de cerveja, ou seja, a empresa não se preocupou em levar ao consumidor uma imagem verdadeira, considerou apenas que a cantora por ser uma pessoa pública e famosa já garantiria o sucesso do produto. Além de a cantora passar a imagem de comportada e não de devassa. Os consumidores não compraram a mensagem e a propaganda não foi o sucesso esperado.

Figura 1: Propaganda Devassa

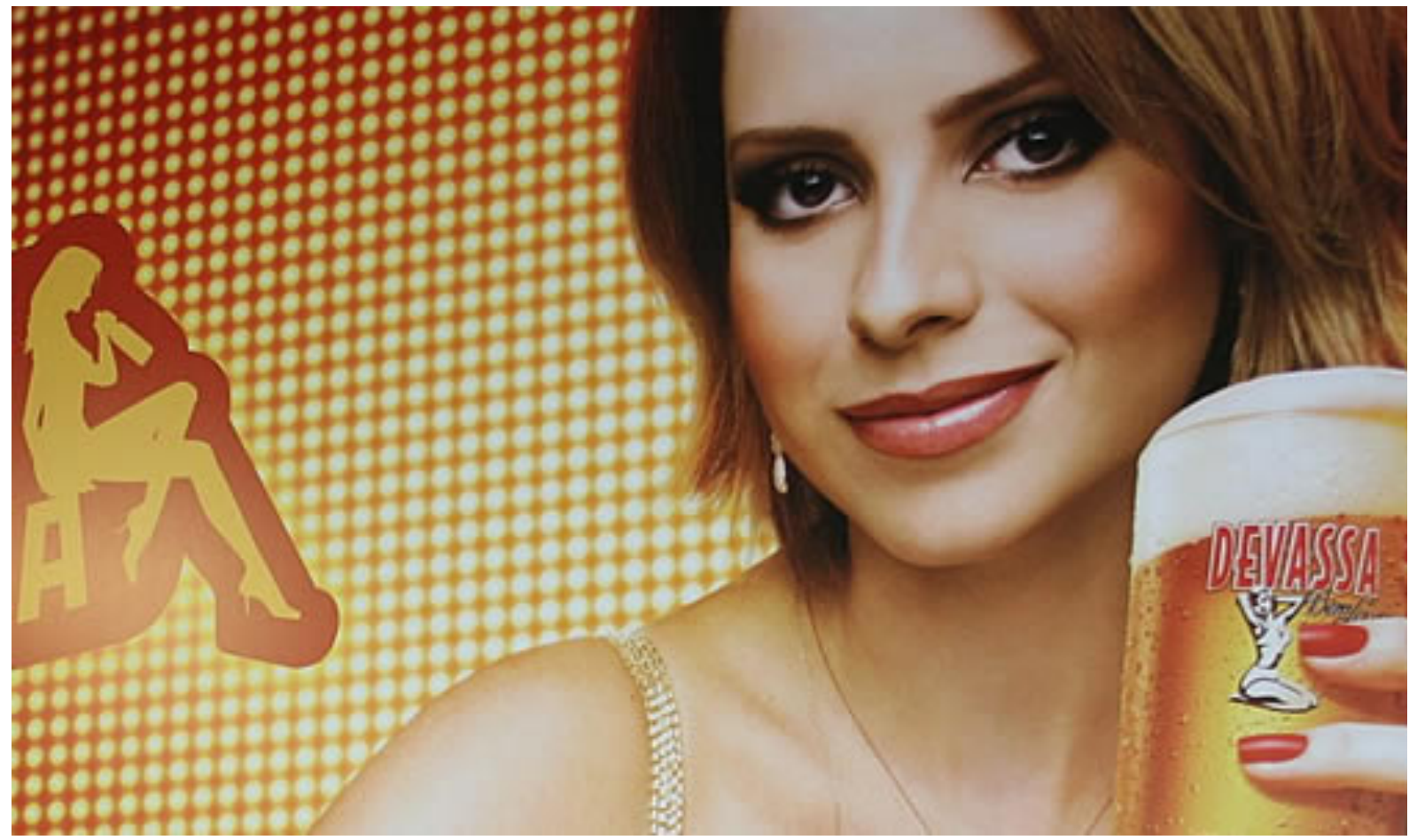

Fonte: http://tyrannusmelancholicus.blogspot.com.br/2011/05/associar-marcasprodutos-celebridades.html

Acessado em: 27/03/2018

Já no próximo exemplo, a celebridade endossadora consegue mostrar ao consumidor que o produto faz realmente parte da sua vida. Na figura 2, o ex-jogador de tênis Gustavo Kuerten é o garoto propaganda da marca de roupas Lacoste. Neste caso, o endosso é perfeito, pois essa marca foi criada por um jogador de tênis e ainda é a patrocinadora de grandes jogadores da atualidade, como Novak Djokovic e Alize Cornet. $O$ endosso aqui se torna claro e válido. O consumidor não se sente enganado e consegue enxergar as possibilidades da compra. 
Figura 2: Guga e Lacoste

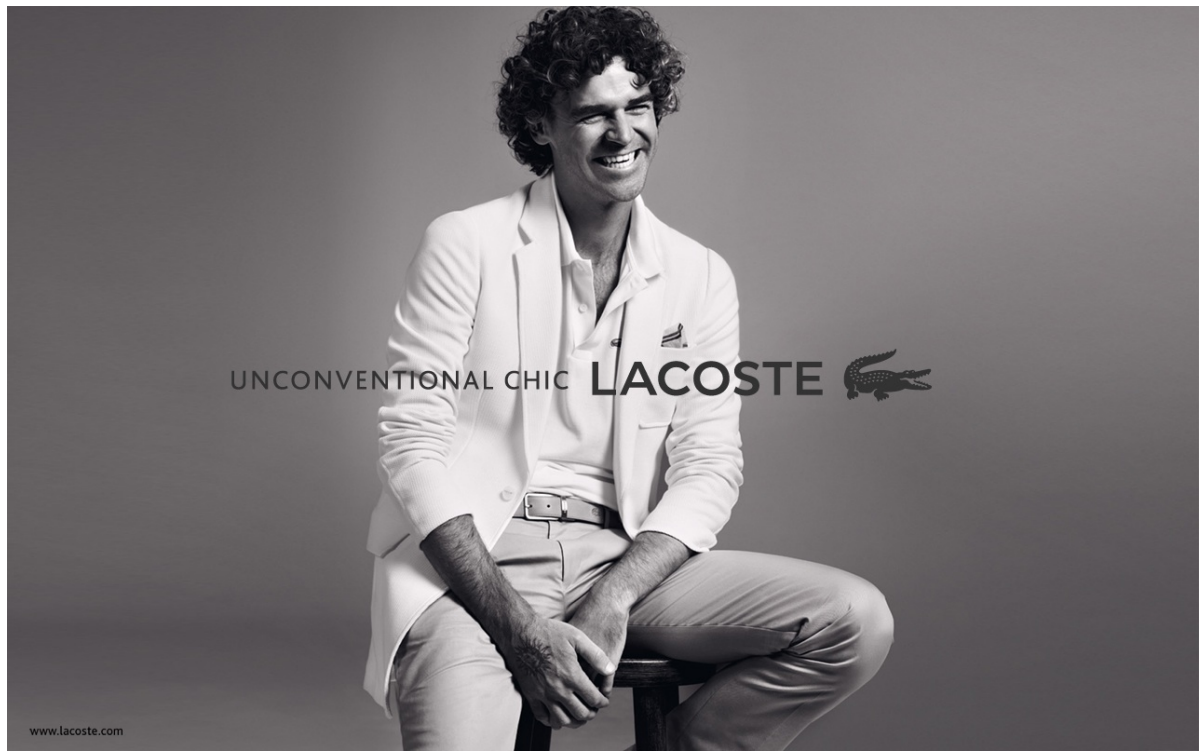

Fonte: http://br.fashionnetwork.com/news/Gustavo-Kuerten-e-o-novo-rosto-da-campanha-Lacoste-UnconventionalChic-,257511.html\#.WrqvylUflFU

Acessado em: $27 / 03 / 2018$

McCraken (2012), nos informa da importância do endosso perfeito no seguinte trecho:

São precisamente os significados da celebridade que a tornam útil para o processo de endosso. Um endosso é bem-sucedido quando molda-se uma associação entre os significados do mundo cultural de um lado e do produto endossado do outro. (MCCRAKEN, 2012 p.115)

A população se interessa pelo mundo das celebridades pois faz parte do cotidiano e a publicidade usa desses significados culturais para divulgar seus produtos e promover tendências de moda, maquiagem, penteados e hábitos, conforme afirma Lipovetsky (2009, p. 248):

As estrelas despertaram comportamentos miméticos em massa, imitou-se amplamente sua maquiagem dos olhos e dos lábios, suas mímicas e posturas; houve até, decorrer dos anos 1930, concursos de sósias de Marlene Dietrich e de Greta Garbo. Mais tarde, os penteados, "rabo de cavalo" ou ondulados de Brigitte Bardot, as aparências descontraídas de James Dean ou Marlon Brando foram modelos em evidência.

A questão é como o consumidor enxerga esses instrumentos de transferência. Segundo McCraken (2012), o consumidor percebe as pessoas, objetos e contexto do anúncio que estão contidos nos produtos e se forem bem trabalhados, o processo de transferência é quase que imediato. Hinerasky (2014, p.7) corrobora dizendo que:

O reconhecimento das marcas em torno do potencial das personalidades levou à recorrente busca por parcerias ou contratação desses operadores individuais na divulgação publicitária, parte das estratégias e da compreensão do mercado contemporâneo.

Vale, ainda, falar do uso das Tshirts como painéis de divulgação de ideias, como a luta mundial contra o câncer de mama, as camisetas do programa de proteção às tartarugas do projeto TAMAR, as camisetas dos médicos sem fronteiras etc. 


\subsection{Novas formas de consumo}

A mudança de pensamento e da forma de consumo que vem se propagando e aumentando no século XXI está fazendo com que as empresas repensem seus propósitos. A nova geração de consumidores não está interessada em comprar o produto por si só, e sim uma causa, um propósito. Esses novos consumidores precisam se sentir parte do produto ou da empresa para consumir. Carvalhal (2016) nos mostra que: "daqui para a frente as marcas que quiserem garantir seu lugar no mundo terão que trilhar o caminho da iluminação, realizando ações com propósito". Os consumidores e as marcas precisarão encontrar sua vocação para compreender o que vai deixar de legado para o planeta. As marcas precisam construir seu lado humano. 0 autor ainda completa:

No velho mundo, o estilo de vida era o maior ponto de atração entre pessoas e marcas. Daqui para frente será substituído cada vez mais pela afinidade entre causas, valores e crenças. No Brasil, $71 \%$ das pessoas só consomem produtos e serviços que se relacionem com seus valores, ideais e crenças, de acordo com a Global GFK... As pessoas que se engajam com o propósito da marca são mais do que apenas "compradores". Elas passam a disseminá-la. Compram não só porque o produto está na moda, é leal ou tem um preço bom, mas porque acreditam na sua causa. (CARVALHAL, 2016)

Segundo o autor, as marcas que não souberem ou não quiserem mostrar esse lado humano não têm chance de sobrevivência no atual mercado consumidor. As pessoas querem consumir produtos de marcas que pensam como elas, que têm os mesmos valores. Para ilustrar tal pensamento, temos dois exemplos de como uma ação de marketing com valores errados pode prejudicar uma empresa. A marca de roupas Maria Filó lançou, em uma de suas coleções, uma estampa que remetia aos tempos da escravidão no Brasil (figura 3). Houve protestos de consumidores que às redes sociais protestar e organizaram boicotes contra a marca. Em resposta, a marca pediu desculpas, disse que não tinha intenção de causar nenhum desconforto e retirou todas as peças de circulação. Por esse exemplo, podemos perceber e entender como a marca conseguiu sair de uma situação ruim que possibilitaria a perda de diversos clientes. A marca se mostrou humana. Errou e pediu desculpas. (figura 4) 

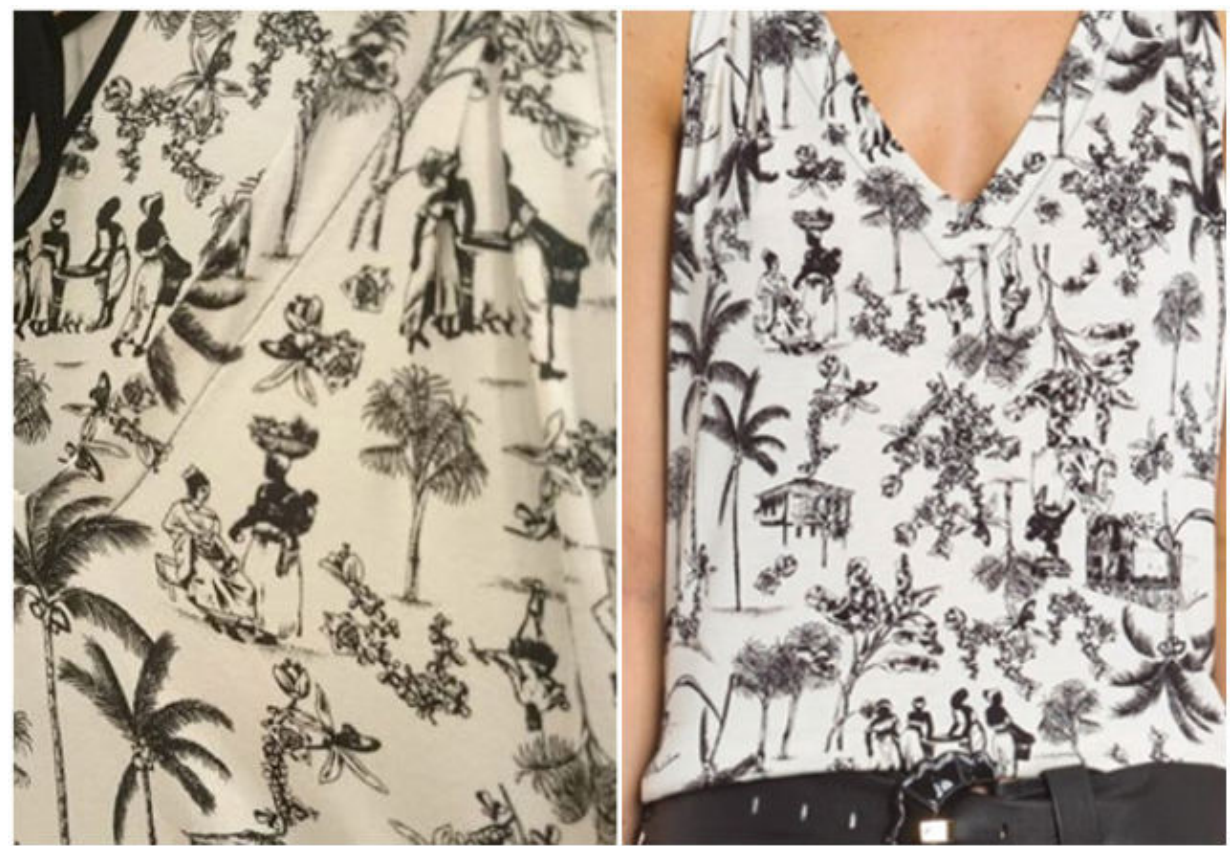

Fonte: https://extra.globo.com/noticias/brasil/estampa-de-escravos-em-colecao-da-maria-filo-foi-alterada-nao-dedebret-diz-pesquisadora-20298194.html

Acessado em: 27/03/2018

Figura 4: Maria Filó

\section{Maria Filó Gostariamos de fazer um esclarecimento. A estampa em questão buscou inspiração na obra de Debret. Em nenhum momento tivemos a intenção de ofender. Pedimos sinceras desculpas e informamos que já estamos tomando as devidas providências para que a estampa seja retirada das lojas.}

\section{Curtir - Responder - 44 min}

Fonte: http://ego.globo.com/famosos/noticia/2016/10/tais-araujo-sobre-estampa-que-retrata-escravos-nao-podeser-vendida.html

Acessado em 27/03/2018

Um exemplo de uma marca que não conseguiu se retratar depois de um comunicado mal sucedido de seu presidente foi a americana Abercrombrie and Fitch. Seu CEO declarou que a marca não produz tamanhos GG e GGG porque não quer pessoas gordas e feias usando suas roupas. Depois da infeliz declaração, as ações da empresa na bolsa caíram vertiginosamente e várias pessoas decidiram doar suas peças para mendigos nas ruas, tirar fotos deles usando a peça e publicar nas redes sociais para mostrar à marca que não concordavam com a posição dela. A marca não conseguiu se retratar e ainda hoje perde muito valor de mercado. Carvalhal (2016) deixa esse sentimento bem claro quando afirma: 
Capitalismo consciente, que visa recontar sua história, restaurando sua verdadeira essência, a de que o propósito de qualquer empresa deve ter a ver com melhorar a vida das pessoas, gerando valor para todas as partes interessadas (clientes, fornecedores, funcionários e até o planeta). Assim vemos estímulo a alugar, pegar emprestado, reutilizar... Às vezes, vender não é necessário. (CARVALHAL, 2016)

Além das formas tradicionais de adquirir produtos, como compra e venda, e troca, existem outras práticas de consumo que estão em voga no mundo de hoje. Os armários compartilhados, por exemplo, encontram cada vez mais adeptos. A prática funciona da seguinte forma: a pessoa pode ir ao armário compartilhado e pegar a roupa que pretende usar durante aquela semana ou período, depois de usados, ela devolve ao armário. A empresa se encarrega de higienizar e passar a roupa para o próximo que queira usar. A quantidade de peças de roupas que o associado pode pegar depende do plano de pagamento que ele preferir adquirir. Além disso, pode também levar roupas próprias e deixar no armário compartilhado, dessa forma, ele ganha algum tipo de benefício quando for pegar roupas no armário.

Outra forma de consumo que não é nova, já existe há bastante tempo, é o aluguel de roupas ou acessórios. Cada vez mais, as pessoas estão alugando vestidos de festas e acessórios, ao invés de os comprar. Aquela história de vestidos alugados com aspecto de sujo e fora de moda já não existe mais. As lojas de aluguel do século XXI são novas e os vestidos estão todos de acordo com as tendências de moda da estação vigente.

Carvalhal (2016) afirma que essa mudança de propósito não está acontecendo apenas na moda e nas roupas, podemos pensar numa mudança global.

\begin{abstract}
A economia baseada nos serviços está substituindo a economia industrial. Isso significada que as marcas de moda não serão mais apenas sobre seus produtos. Elas precisam entender que não devem ser apenas sobre roupas. Devemos ampliar nossa ideia sobre serviço. É o serviço para a Terra, para a totalidade da ecoexistência, que vai criar postos de trabalho e materialização no futuro. Será que precisamos de mais roupas? De mais marcas de roupas? Ou precisamos de profundidade, de marcas que tenham propósito e que entendam que seu pape vai bem além de apenas vender? (CARVALHAL, 2016)
\end{abstract}

\title{
3 Conclusão
}

Percebe-se que as práticas de consumo alteram-se de acordo com as mudanças da sociedade. Durante muito anos a única forma de consumir produtos, sejam eles de moda ou subsistência, foi o escambo ou troca. As pessoas trocavam serviços ou produtos que não tinham por bens que precisavam. Depois do escambo, surgiram as moedas, e as compras passaram a ser feitas usando essa prática. O vendedor colocava um preço em dinheiro e o comprador usava a moeda local para adquirir o que necessitava ou simplesmente desejava. Essa ainda é a forma de consumo mais usada, porém, entendemos que já existem outras formas de possuir algo. A troca de produtos e o compartilhamento têm sido bastante usado pelas pessoas hoje em dia.

O consumidor está mais atento ao que compra e como compra. Esse consumidor não é mais influenciado tão rapidamente pelas imagens e discursos vazios. O consumidor do século XXI pensa antes de comprar e busca se aproximar de produtos que harmonizam-se com o seu projeto de vida. As empresas precisam compreender que se não tiver um propósito ou uma filosofia da marca que agrade o público-alvo, a probabilidade de insucesso é grande. Segundo Carvalhal (2016), as transformações precisam vir de dentro das empresas e cita: 
As transformações agora precisam ser de dentro para fora. Marcas com propósito só poderão ser de dentro para fora. Marcas com propósito só poderão ser construídas por pessoas com propósito de vida. Então se existe um novo sentido a ser resgatado, ele está dentro de nós. (CARVALHAL, 2016)

O grande desafio para os designers e para os desenvolvedores de novos produtos é entender que os consumidores estão mais conscientes em relação ao que compram e que os discursos sem critérios e contraditórios das celebridades não encontrarão repercussão. Esse novo consumidor está mais propício a adquirir produtos e serviços que tenham propósito e estejam alinhados com o projeto de vida do próprio consumidor.

\section{Referências Bibliográficas}

- BAUMAN, Zygmunt. Vida para consumo: a transformação das pessoas em mercadoria. Rio de Janeiro: Zahar, 2008.

- CARVAlHAL, André Luiz Braga. Moda com Propósito: manifesto pela grande virada. 1 ed. São Paulo: Paralela, 2016.

- COlOMBO, L. O. R.; FAVOTO, T. B.; CARMO, S. N. A evolução da sociedade de consumo. Akrópólis, Umuarama, v. 16, n. 3, p. 143-149, jul./set. 2008.

- HINERASKY, Daniela Aline. O Instagram Como Plataforma De Negócio de Moda: dos “itbloggers" às "it-marcas" In: Congresso Internacional de Comunicação e Consumo (Comunicon), 8 a 10 out.2014. Anais do Congresso Internacional de Comunicação e Consumo (Comunicon), 2014 ISBN:978-85-99790-21-2 - Disponível em: http://www.espm.br/download/Anais_Comunicon_2014/links/GT06.html

- LIPOVETSKY, Gilles. O Império do Efêmero: a moda e seu destino nas sociedades modernas. Sao Paulo: Companhia das Letras, 2009

- MADUREIRA, Eduardo Miguel Prata - O escambo na contemporaneidade: 0 álbum da copa do mundo como simulador do comércio primitivo - III Congresso Nacional de Pesquisa em Ciências Sociais Aplicadas - III CONAPE 1 Francisco Beltrão/PR, 01, 02 e 03 de outubro de 2014

- MCCRAKEN, Grant. Cultura \& Consumo II. Rio de Janeiro: Mauad, 2012.

- SCHULTE, Neide Köhler; LOPES, Luciana Dornbusch. Sustentabilidade ambiental: um desafio para a moda. ModaPalavra e-periódico, v. 1, n. 2, 2008 